\title{
Article \\ Smart Design of Mitochondria-Targeted and ROS-Responsive CPI-613 Delivery Nanoplatform for Bioenergetic Pancreatic Cancer Therapy
}

\author{
Yi-Mei Zhang ${ }^{1,2}{ }^{2}$, Meng Xia ${ }^{1}$, Rui Ao ${ }^{1}$, Li-Xia Gao ${ }^{1}$, Yan Tang ${ }^{1}$, Jiu-Hong Huang ${ }^{1}$, Ya-Fei Luo ${ }^{1}$, \\ Zhong-Zhu Chen ${ }^{1}$, Bo-Chu Wang ${ }^{2}$ and Zheng Huang ${ }^{1, *}$
}

Citation: Zhang, Y.-M.; Xia, M.; Ao, R.; Gao, L.-X.; Tang, Y.; Huang, J.-H.; Luo, Y.-F.; Chen, Z.-Z.; Wang, B.-C.; Huang, Z. Smart Design of Mitochondria-Targeted and ROS-Responsive CPI-613 Delivery Nanoplatform for Bioenergetic Pancreatic Cancer Therapy. Nanomaterials 2021, 11, 2875. https:// doi.org/10.3390/nano11112875

Academic Editors: Abdelhamid Elaissari and Jose L. Luque-Garcia

Received: 4 September 2021

Accepted: 26 October 2021

Published: 28 October 2021

Publisher's Note: MDPI stays neutral with regard to jurisdictional claims in published maps and institutional affiliations.

Copyright: (c) 2021 by the authors. Licensee MDPI, Basel, Switzerland. This article is an open access article distributed under the terms and conditions of the Creative Commons Attribution (CC BY) license (https:// creativecommons.org/licenses/by/ $4.0 /)$.
1 National \& Local Joint Engineering Research Center of Targeted and Innovative Therapeutics, Chongqing Key Laboratory of Kinase Modulators as Innovative Medicine, College of Pharmacy \& International Academy of Targeted Therapeutics and Innovation, Chongqing University of Arts and Sciences, Chongqing 402160, China; yimeizhang@cqwu.edu.cn (Y.-M.Z.); xm269691792@163.com (M.X.); aor1027@163.com (R.A.); LixiaGao@cqwu.edu.cn (L.-X.G.); 20160063@cqwu.edu.cn (Y.T.); jhhuang@cqwu.edu.cn (J.-H.H.); luoyf@cqwu.edu.cn (Y.-F.L.); 18883138277@163.com (Z.-Z.C.)

2 Key Laboratory of Bio-Theological Science and Technology of Ministry of Education, College of Bioengineering, Chongqing University, Chongqing 400045, China; wangbc2000@126.com

* Correspondence: zhenghuang@cqwu.edu.cn; Tel.: +86-023-6116-2702

Abstract: Mitochondria, as the powerhouse of most cells, are not only responsible for the generation of adenosine triphosphate (ATP) but also play a decisive role in the regulation of apoptotic cell death, especially of cancer cells. Safe potential delivery systems which can achieve organelletargeted therapy are urgently required. In this study, for effective pancreatic cancer therapy, a novel mitochondria-targeted and ROS-triggered drug delivery nanoplatform was developed from the TPP-TK-CPI-613 (TTCI) prodrug, in which the ROS-cleave thioketal functions as a linker connecting mitochondrial targeting ligand TPP and anti-mitochondrial metabolism agent CPI-613. DSPEPEG2000 was added as an assistant component to increase accumulation in the tumor via the EPR effect. This new nanoplatform showed effective mitochondrial targeting, ROS-cleaving capability, and robust therapeutic performances. With active mitochondrial targeting, the formulated nanoparticles (TTCI NPs) demonstrate much higher accumulation in mitochondria, facilitating the targeted delivery of CPI-613 to its acting site. The results of in vitro antitumor activity and cell apoptosis revealed that the $\mathrm{IC}_{50}$ values of TTCI NPs in three types of pancreatic cancer cells were around $20 \sim 30 \mu \mathrm{M}$, which was far lower than those of CPI-613 $(200 \mu \mathrm{M}) ; 50 \mu \mathrm{M}$ TTCI NPs showed an increase in apoptosis of up to $97.3 \%$ in BxPC3 cells. Therefore, this mitochondria-targeted prodrug nanoparticle platform provides a potential strategy for developing safe, targeting and efficient drug delivery systems for pancreatic cancer therapy.

Keywords: mitochondria-targeting; ROS-responsive; drug delivery; nanoparticles; pancreatic cancer therapy; CPI-613

\section{Introduction}

Pancreatic cancer, known as the "king of cancers", is the fourth leading cause of cancer mortality in the world and its prognosis is cruel: the five-year survival rate remains lower than $10 \%$ [1,2]. CPI-613, a member of a novel class of anti-cancer lipoate derivatives, is an anti-mitochondrial metabolism agent which strongly induces apoptosis by disrupting mitochondrial metabolism, such as by changing mitochondrial enzyme activities and redox status in several types of cancer cells, especially in pancreatic cancer and small lung cancer cells [3,4]. CPI-613 has exhibited prominent antitumor activity against human pancreatic cancer in xenograft models, with low side-effects thanks to its specificity and selectivity for tumor cells [5-7]. CPI-613 has been approved as an orphan drug for the treatment 
of pancreatic cancer as well as other diseases by the U.S. Food and Drug Administration (FDA) [8].

Targeted drug delivery systems (DDSs) using passive targeting via the "enhanced permeability and retention (EPR) effect" or via active targeting for chemotherapy provide a beneficial strategy to improve antitumor efficiency and reduce side effects by promoting greater accumulation of delivered cargos at target sites [9]. Most DDS to date concentrate more on cellular internalization using receptors on the plasma membrane of certain cells which they specifically recognize and interact with [10]. However, the action sites of most clinically approved chemotherapeutic drugs (CPI-613, for instance) are focused on certain organelles within specific cells [11]. Herein, the DDS concentrates on certain organelles such as the nucleus and the mitochondria within specific cells, a method which has gradually garnered increasing interest for its further improvement the therapeutic effect [12].

It is well known that mitochondria are the powerhouse of most eukaryotic cells and play a crucial role in cellular metabolism. Mitochondria are responsible for various significant features, such as providing cellular energy by generating adenosine triphosphate (ATP), generation of reactive oxygen species (ROS), and regulating apoptotic cell death $[13,14]$. Mitochondria have been treated as interesting targets in organelle-targeted therapy, since they play pivotal roles in regulating cell survival and death. Thus, targeting mitochondria with therapeutic drugs presents plenty of advantages. Primarily, potential off-target toxic side-effects on normal tissues can be prevented if the drugs are targeted for delivery to the organelles. Furthermore, lower doses of drug administration could be approved by improving the bioavailability of the drugs at the target side, leading to maximized therapeutic efficiency $[15,16]$. Therefore, an increasing number of mitochondria-targeting DDS have been developed to promote active targeting via nanoplatform [15,17-19]. Among these, triphenylphosphonium (TPP), a lipophilic cation which has revealed a high affinity for mitochondria with about 1000-fold accumulation in this organelle [20], is one of the most widely used mitochondria targeting groups. The conjugation of TPP with therapeutic drugs has been developed to confirm mitochondria targeting [21-23]. However, until now few studies have been conducted on the targeted delivery of chemotherapeutic drugs such as CPI-613, whose action sites are focused on mitochondria.

Drug release behavior has an important impact on therapeutic efficiency and is one of the most vital factors to be considered in the design of a DDS. As mentioned above, mitochondria are the main centre for the production of ROS (for example, $\mathrm{OH}-$ ), $\mathrm{O}_{2}-$, $\mathrm{H}_{2} \mathrm{O}_{2}$ ) as byproducts of ATP generation [24-26]. Therefore, the high levels of intracellular ROS in cancer cells could be faultlessly utilized as a unique cancer-related stimulus to mediate drug delivery. It has been reported that thioketal groups can be readily cleaved in ROS-abundant conditions [27-29], which has inspired us to develop ROS-responsive controlled drug release in mitochondria.

Considering the unique features of anti-mitochondrial metabolism agent (CPI-613) and the high levels of ROS in mitochondria, mitochondrial targeting ligand (TPP) and biodegradable thioketal linkages, it is desirable to conjugate CPI-613 and TPP with biodegradable ROSresponsive thioketal linkages in order to exploit novel mitochondrial targeting DDS. In this study, we present a smart nanoplatform for active mitochondrial targeting and ROSresponsive drug release. First, the mitochondrial targeting ligand TPP was conjugated onto thioketal linkages (TPP-TK). Then, CPI-613 was combined by esterification (TTP-TK-CPI613). Aiming for better tumor targeting and good biocompatibility, DSPE-PEG2000 was employed as an assistant component in order to increase the accumulation in the tumor via the EPR effect. This novel nanoplatform shows the following unique properties: (1) The hydrophilic PEG2000 shell can stabilize the DDS, prolong circulation in blood, and increase accumulation in the tumor; (2) TPP can facilitate the targeted delivery of CPI-613 to its acting site; (3) The TK-containing linker can promote ROS-triggered drug release; and finally (4) It has good biocompatibility and is highly biodegradable. Therefore, the smart nanoplatform will be able to encapsulate anti-mitochondrial metabolism agent (CPI-613), 
contain a TPP passive mitochondrial targeting moiety, and release ROS-triggered drugs to improve drug delivery ability and therapeutic efficacy in pancreatic cancer cell lines. Overall, the prepared multifunctional DDS exhibits multiple advantages including an efficient TPP-mediated mitochondria-targeted delivery method, good biocompatibility and biodegradability, a rapid ROS-triggered drug release, and great potential for chemotherapy in pancreatic cancer.

\section{Materials and Methods}

All chemicals and reagents were obtained commercially and were used as received. Mercaptoacetic acid was purchased from Aladdin Reagent Company (Shanghai, China). Cholesterol and rhodamine B base were purchased from BBI Life Sciences (Shanghai, China). CPI-613 was purchased from Bidepharm Reagent Company (Shanghai, China). 1,2-distearoyl-sn-glycero-3-phosphoethanolamine-N-[methoxy (polyethylene glycol)-2000] (ammonium salt) (DSPE-PEG2000) was purchased from Avanti Polar Lipids (Birmingham, AL, USA). The products were purified by Biotage Isolera ${ }^{\mathrm{TM}}$ Spektra Systems. A Bruker 400 spectrometer was used for recording ${ }^{1} \mathrm{H}$ and ${ }^{13} \mathrm{C}$ NMR. HPLC-MS analyses were performed on a LCMS-2020 instrument (Shimadzu, Kyoto, Japan) using the following conditions: Shim-pack VPODS $C_{18}$ column (reverse phase, $150 \mathrm{~mm} \times 2.0 \mathrm{~mm}$ ); 80\% acetonitrile and $20 \%$ water over $6.0 \mathrm{~min}$; flow rate of $0.4 \mathrm{~mL} / \mathrm{min}$; UV photodiode array detection from 200 to $300 \mathrm{~nm}$.

3-(4,5-Dimethylthiazol-2-yl)-2,5-diphenyltetrazolium bromide (MTT) was purchased form Sangon Biotech (A600799-0005, Shanghai, China). Mito-Tracker Green and Annexin V-FITC Apoptosis Detection Kit were purchased from Beyotime Biotechnology (Shanghai, China).

\subsection{Synthesis of Prodrug TTCI}

\subsubsection{Synthesis of Compounds 1 and 2}

Compounds 1 and 2 were obtained according to the previous literature [30,31]. Briefly, 3-mercptopropionic acid ( $5 \mathrm{~g}, 47.2 \mathrm{mmol})$, anhydrous acetone (1.3 g, $21.46 \mathrm{mmol})$, and trifluoroacetic acid $(20 \mu \mathrm{L})$ were mixed in a $100 \mathrm{~mL}$ round-bottom flask. After stirring overnight at room temperature, a white solid was precipitated. The solid was filtered and washed several times with ice-cold deionized water and hexane. After drying in vacuum, compound 1 was obtained as a white crystalline powder (yield: $90 \%) .1 \mathrm{H} \mathrm{NMR}\left(\mathrm{CDCl}_{3}\right.$, $400 \mathrm{MHz}): \delta(\mathrm{ppm})=2.92-2.88\left(\mathrm{t}, 4 \mathrm{H},-\mathrm{CH}_{2}-\right), 2.70-2.66\left(\mathrm{t}, 4 \mathrm{H},-\mathrm{CH}_{2}-\right), 1.60\left(\mathrm{~s}, 6 \mathrm{H},-\mathrm{CH}_{3}\right)$; $13 \mathrm{C} \mathrm{NMR}\left(\mathrm{CDCl}_{3}, 100 \mathrm{MHz}\right): \delta(\mathrm{ppm})=178.44,56.50,33.50,30.73,24.86$.

Compound 2 was obtained by the reduction of LiAlH4 on compound 1. Briefly, compound 1 ( $1.0 \mathrm{~g}, 4 \mathrm{mmol})$ was dissolved in $30 \mathrm{~mL}$ of anhydrous THF under magnetic stirring. LiAlH4 $(0.9 \mathrm{~g}, 24 \mathrm{mmol})$ was slowly added into the reaction mixture. The mixed reaction solution was heated to reflux for $2 \mathrm{~h}$. Then, $0.9 \mathrm{~mL} \mathrm{NaOH}(w / w 15 \%)$ aqueous solution and $0.9 \mathrm{~mL}$ water were added to the flask. After filtration, the solvent was concentrated and dried in vacuum overnight to give compound 2 as a colorless oil (yield: 87\%). 1H NMR $\left(\mathrm{CDCl}_{3}, 400 \mathrm{MHz}\right): \delta(\mathrm{ppm})=3.77-3.74\left(\mathrm{t}, 4 \mathrm{H},-\mathrm{CH}_{2}-\right), 2.77-2.74(\mathrm{t}$, $\left.4 \mathrm{H},-\mathrm{CH}_{2}-\right), 1.89-1.82\left(\mathrm{~m}, 4 \mathrm{H},-\mathrm{CH}_{2}-\right), 1.61\left(\mathrm{~s}, 6 \mathrm{H},-\mathrm{CH}_{3}\right) .{ }^{13} \mathrm{C} \mathrm{NMR}\left(\mathrm{CDCl}_{3}, 100 \mathrm{MHz}\right)$ : $\delta(\mathrm{ppm})=172.93,135.28,133.46,133.37,130.67,130.55,118.17,117.31,63.70,61.72,56.01$, $38.6,31.94,30.90,28.21,26.70,26.56,17.85$.

\subsubsection{Synthesis of Compound 3}

3-Carboxypropyltriphenylphosphonium bromide $(637 \mathrm{mg}, 1.483 \mathrm{mmol}$ ) was dissolved in DCM; 4-Dimethylamino-pyridine (DMAP, $217 \mathrm{mg}, 1.78 \mathrm{mmol}$ ) and $N, N$-dicyclohexylcarbodiimide (DCC, $367 \mathrm{mg}, 1.78 \mathrm{mmol}$ ) were added successively at $0{ }^{\circ} \mathrm{C}$ for $30 \mathrm{~min}$. Then, compound 2 (400 mg, $1.78 \mathrm{mmol}$ ) was added to the mixed solution. After reaction at room temperature overnight, the reaction solution was cooled to $-20^{\circ} \mathrm{C}$. Filtration was performed and the filtrate was concentrated. After purification by column chromatography over silica gel eluting with a gradient of $\mathrm{CH}_{3} \mathrm{OH} / \mathrm{CH}_{2} \mathrm{Cl}_{2}(0$ to $5 \%)$, compound 3 was obtained as colorless oil (yield: $84 \%)$. 1H NMR $\left(\mathrm{CDCl}_{3}, 400 \mathrm{MHz}\right): \delta(\mathrm{ppm})=7.90-7.64(\mathrm{~m}$, 
$15 \mathrm{H},-\mathrm{CH}-), 4.21-4.11\left(\mathrm{q}, 2 \mathrm{H},-\mathrm{CH}_{2}-\right), 3.36-3.22\left(\mathrm{~m}, 2 \mathrm{H},-\mathrm{CH}_{2}-\right), 2.73-2.59\left(\mathrm{~m}, 6 \mathrm{H},-\mathrm{CH}_{2}-\right)$, 1.94-1.84 (m, 6H, $\left.-\mathrm{CH}_{2}-\right)$, 1.84-1.75 (m, 2H, $\left.-\mathrm{CH}_{2}-\right), 1.57\left(\mathrm{~s}, 6 \mathrm{H},-\mathrm{CH}_{3}\right)$.

\subsubsection{Synthesis of Prodrug TTCI}

CPI-613 (50 mg, $0.128 \mathrm{mmol}$ ) was dissolved in anhydrous DCM; 4-Dimethylaminopyridine (DMAP, $19 \mathrm{mg}, 0.155 \mathrm{mmol}$ ) and $\mathrm{N}, \mathrm{N}$-dicyclohexyl- carbodiimide (DCC, $32 \mathrm{mg}$, $0.155 \mathrm{mmol})$ were added successively at $0{ }^{\circ} \mathrm{C}$ for $30 \mathrm{~min}$. Then, compound $3(98 \mathrm{mg}$, $0.155 \mathrm{mmol}$ ) was added to the mixed solution. After stirring at room temperature overnight, the reaction solution was cooled to $-20^{\circ} \mathrm{C}$. Filtration was performed and the filtrate was concentrated. After purification by column chromatography over silica gel eluting with a gradient of $\mathrm{CH}_{3} \mathrm{OH} / \mathrm{CH}_{2} \mathrm{Cl}_{2}(0$ to $7 \%)$, prodrug TTCI was obtained as colorless oil (yield: $41 \%$ ).

1H NMR $\left(\mathrm{CDCl}_{3}, 400 \mathrm{MHz}\right): \delta(\mathrm{ppm})=7.90-7.69(\mathrm{~m}, 15 \mathrm{H},-\mathrm{CH}-), 7.31-7.27(\mathrm{~m}, 5 \mathrm{H}$, $-\mathrm{CH}-), 7.25-7.19(\mathrm{~m}, 2 \mathrm{H},-\mathrm{CH}-), 4.13-4.12\left(\mathrm{q}, 4 \mathrm{H},-\mathrm{CH}_{2}-\right), 3.66-3.64\left(\mathrm{~d}, 4 \mathrm{H},-\mathrm{CH}_{2}-\right), 2.89$ $\left(\mathrm{t}, 2 \mathrm{H},-\mathrm{CH}_{2}-\right)$ 2.66-2.62 (t, 4H, $\left.-\mathrm{CH}_{2}-\right), 2.60-2.53\left(\mathrm{t}, 1 \mathrm{H},-\mathrm{CH}_{2}-\right), 2.53-2.46\left(\mathrm{t}, 2 \mathrm{H},-\mathrm{CH}_{2}-\right)$, $2.24-2.23\left(\mathrm{t}, 2 \mathrm{H},-\mathrm{CH}_{2}-\right), 1.92-1.88(\mathrm{~m}, 6 \mathrm{H},-\mathrm{CH}-), 1.89-1.82\left(\mathrm{~m}, 4 \mathrm{H},-\mathrm{CH}_{2}-\right), 1.73-1.71(\mathrm{~m}$, $\left.2 \mathrm{H},-\mathrm{CH}_{2}-\right), 1.58\left(\mathrm{~s}, 6 \mathrm{H},-\mathrm{CH}_{3}\right), 1.53-1.49\left(\mathrm{t}, 2 \mathrm{H},-\mathrm{CH}_{2}-\right), 1.47-1.41\left(\mathrm{t}, 2 \mathrm{H},-\mathrm{CH}_{2}-\right) .{ }^{13} \mathrm{C}$ $\operatorname{NMR}\left(\mathrm{CDCl}_{3}, 100 \mathrm{MHz}\right): \delta(\mathrm{ppm})=173.52,173.24,138.65,138.49,134.97,133.83,133.73$, $130.50,130.38,128.89,128.85,128.50,128.45,126.97,126.93,118.74,117.89,63.64,63.23,56.01$, $44.28,36.38,35.13,34.45,34.12,30.94,28.73,28.65,26.61,26.16,24.74,14.13$. HRMS (ESI): $\mathrm{m} / \mathrm{z}$ calculated for $\mathrm{C}_{53} \mathrm{H}_{66} \mathrm{O}_{4} \mathrm{PS}_{4}+[\mathrm{M}]$ 925.3576; found 925.3582.

\subsubsection{Synthesis of Cholesterol Analogue TTCh}

Cholesterol ( $1.0 \mathrm{~g}, 2.59 \mathrm{mmol})$ and succinic anhydride $(0.776 \mathrm{~g}, 7.76 \mathrm{mmol})$ were dissolved in DCM at $0{ }^{\circ} \mathrm{C}$; 1,8-Diazabicyclo (5.4.0) undec-7-ene (DBU, $1.179 \mathrm{~g}, 7.76 \mathrm{mmol}$ ) was slowly added to the reaction solution, and the reaction was stirred at room temperature for $4 \mathrm{~h}$. The solution was acidified with $1 \%$ aqueous $\mathrm{HCl}$ solution, and DCM was added. The organic layer was collected and evaporated. The product was obtained after purification by column chromatography over silica gel eluting with a gradient of $\mathrm{CH}_{3} \mathrm{OH} / \mathrm{CH}_{2} \mathrm{Cl}_{2}$ (0 to 6\%). The upper product $(75 \mathrm{mg}, 0.155 \mathrm{mmol}$ ) was dissolved in anhydrous DCM; 4Dimethylamino-pyridine (DMAP, $19 \mathrm{mg}, 0.155 \mathrm{mmol}$ ) and $N, N$-dicyclohexyl-carbodiimide (DCC, $32 \mathrm{mg}, 0.155 \mathrm{mmol}$ ) were added successively at $0{ }^{\circ} \mathrm{C}$ for $30 \mathrm{~min}$. Then, compound 3 (98 $\mathrm{mg}, 0.155 \mathrm{mmol}$ ) was added to the mixed solution. After stirring at room temperature overnight, the reaction solution was cooled to $-20^{\circ} \mathrm{C}$. Filtration was performed and the filtrate was concentrated. After purification by column chromatography over silica gel eluting with a gradient of $\mathrm{CH}_{3} \mathrm{OH} / \mathrm{CH}_{2} \mathrm{Cl}_{2}$ (0 to $6 \%$ ), TTCh was obtained as colorless oil (yield: 62\%).

$1 \mathrm{H} \mathrm{NMR}\left(\mathrm{CDCl}_{3}, 400 \mathrm{MHz}\right): \delta(\mathrm{ppm})=7.85-7.65(\mathrm{~m}, 15 \mathrm{H},-\mathrm{CH}-), 5.40-5.32(\mathrm{~m}, 1 \mathrm{H},-$ CH-), 4.66-4.55 (m, 1H, -CH-), 4.24-4.11 (t, 4H, - $\left.\mathrm{CH}_{2}-\right)$, 3.40-3.28 (d, 2H, $\left.-\mathrm{CH}_{2}-\right)$, 2.75-2.54 $\left(\mathrm{m}, 10 \mathrm{H},-\mathrm{CH}_{2}-\right), 2.35-2.26\left(\mathrm{~d}, 2 \mathrm{H},-\mathrm{CH}_{2}-\right), 2.06-1.79(\mathrm{~m}, 12 \mathrm{H}), 1.58\left(\mathrm{~s}, 6 \mathrm{H},-\mathrm{CH}_{3}\right), 1.60-0.76$ $(\mathrm{m}, 35 \mathrm{H}) .13 \mathrm{C} \mathrm{NMR}\left(\mathrm{CDCl}_{3}, 100 \mathrm{MHz}\right): \delta(\mathrm{ppm})=172.89,172.33,171.70,139.60,135.29$, 133.48, 133.38, 130.67, 130.55, 122.68, 118.20, 117.35, 74.36, 63.79, 63.61, 56.70, 56.14, 55.98, $50.03,42.31,39.73,39.52,38.06,36.96,36.59,36.19,35.79,32.73,31.91,31.85,30.90,29.70$, 29.47, 29.19, 28.54, 28.41, 28.23, 28.01, 27.74, 26.56, 24.29, 23.89, 22.82, 22.57, 21.45, 21.03, 19.32, 18.72, 17.89, 11.86. HRMS (ESI): $m / z$ calculated for $\mathrm{C}_{62} \mathrm{H}_{88} \mathrm{O}_{6} \mathrm{PS}_{2}+[\mathrm{M}]$ 1023.5754; found 1023.5779 .

\subsection{Preparation of Nanoparticles (NPS)}

TTCI, TTCI/Rho and TTCh NPs were formed using the filming-rehydration method. The additional lipid 1,2-distearoyl-sn-glycero-3-phosphoethanolamine-N-[methoxy (polyethylene glycol)-2000] (ammonium salt) (DSPE-PEG2000) was used to form nanoparticles. First, TTCI NPs with the different proportions were made up by prodrug TTCI and DSPE-PEG2000 in 1:x (mol:mol), and the $x$ was range 0.05-0.30. The prodrugs TTCI and DSPE-PEG2000 were mixed in a little glass vial and dissolved in $2.5 \mathrm{~mL}$ anhydrous 
chloroform/methanol solution $(3 / 1, v / v)$. The thin films were obtained by slowly rotaryevaporating the solvent and further dried under vacuum overnight. Then, thin films were hydrated with $2.5 \mathrm{~mL}$ of PBS buffer $\left(10 \mathrm{mM}\right.$, pH 7.4) at $70{ }^{\circ} \mathrm{C}$ for $30 \mathrm{~min}$. After $10 \mathrm{~min}$ tip-sonication ( $3 \mathrm{~s}$ on, $3 \mathrm{~s}$ off), TTCI NPs were obtained. The same method was used to prepare TTCh NPs, in which TTCh and DSPE-PEG2000 were only in 1:0.2 (mol:mol). In order to observe intracellular distribution, TTCI/Rho NPs were also prepared using the same method. TTCI/Rho NPs were made up with TTCI, DSPE-PEG2000 and Rhodamine B base with 1:0.2:0.2 (mol:mol:mol). The final concentration of prodrug TTCI or TTCh was $1 \mathrm{mM}$. If not specified, TTCI NPs were made up by TTCI and DSPE-PEG2000 with 1:0.2 (mol:mol).

\subsection{Characterization of TTCI NPS}

A dynamic light scattering (DLS) Zetasizer nano zsp instrument (Malvern instruments Led) was used to measure the diameter distribution at room temperature. The size of TTCI NPs with different proportions was first characterized. $200 \mu \mathrm{L}$ TTCI NPs (different proportions, $1 \mathrm{mM}$ ) were diluted with deionized water to produce $1 \mathrm{~mL}$ aqueous solution. The diameter distribution of the diluted aqueous solution was measured at room temperature.

The morphology of TTCI NPs (TTCI:DSPE-PEG2000 $=1: 0.2(\mathrm{~mol}: \mathrm{mol})$ ) was observed by transmission electron microscopy (TEM) on a JEM-1400plus system (JEOL, Japan); $30 \mu \mathrm{L}$ TTCI NPs ( $1 \mathrm{mM}$ ) was diluted to $100 \mu \mathrm{L}$ aqueous solution and mixed together. The diluted solution was applied to a copper grid and $0.2 \%(w / v)$ phosphotungstic acid aqueous solution was used to stain the samples.

\subsection{ROS-Triggered Disassembly Studies of TTCI NPs}

The $1 \mathrm{~mL}$ mixed aqueous solutions containing $200 \mu \mathrm{L}$ TTCI NPs under $\mathrm{H}_{2} \mathrm{O}_{2}(200 \mathrm{mM}$ or $700 \mathrm{mM}$ ) were incubated at $37^{\circ} \mathrm{C}$. At appropriate intervals, the size changes were monitored by DLS.

\subsection{Cell Culture}

Human pancreatic cancer cell lines AsPC-1, PANC-1 and BxPC3 were purchased from the American Type Culture Collection (ATCC, Rockville, MD, USA). AsPC-1 and PANC-1 cells were cultured in RPMI1640 medium containing 10\% fetal bovine serum (FBS). The BxPC3 cells were cultured in DMEM medium containing 10\% FBS. Cells were cultivated at $37^{\circ} \mathrm{C}$ in a humidified incubator supplied with $5 \% \mathrm{CO}_{2}$.

\subsection{Cell Viability Assay}

The effect on pancreatic cancer cells of TTCI NPs in different proportions was measured with an MTT assay. AsPC- 1 and PANC-1 cells were counted and seeded into 96-well plates (6000 cells/well) with $100 \mu \mathrm{L}$ cell medium and incubated for $24 \mathrm{~h}$. The cells were treated with another $100 \mu \mathrm{L}$ of complete medium containing increasing concentrations of TTCI NPs in different proportions. After incubation for $48 \mathrm{~h}, 20 \mu \mathrm{L}$ MTT solution $(5 \mathrm{mg} / \mathrm{mL}$ ) was added. After $4 \mathrm{~h}$ incubation, the original medium was removed and $200 \mu \mathrm{L}$ dimethylsulfoxide (DMSO) was added to each well. The plate was shaken on the table shaker for $10 \mathrm{~min}$. Next, the absorbance was measured at $570 \mathrm{~nm}$ by a microplate reader (Bio-Tek, Winooski, VT, USA). All experiments were repeated three times.

The cell viability of TTCI NPs (TTCI:DSPE-PEG2000 $=1: 0.2(\mathrm{~mol}: \mathrm{mol})$ ) and TTCh NPs (TTCh:DSPE-PEG2000 = 1:0.2 (mol:mol)) on AsPC-1 and PANC-1 cells was determined by the same method. The cells were treated with complete medium containing increasing concentrations of TTCI NPs or TTCh NPs.

The cell viability of TTCI NPs (TTCI:DSPE-PEG2000 $=1: 0.2(\mathrm{~mol}: \mathrm{mol}))$ and CPI-613 on AsPC-1, PANC-1 and BxPC3 was also determined by the same method. The cells were incubated with complete medium containing increasing concentrations of TTCI NPs and CPI-613. 


\subsection{Cell Proliferation and Growth}

The effect of TTCI NPs on proliferation and growth in pancreatic cancer cells at different time points was observed by using the High Content analysis system (PerkinElmer, Waltham, MA, USA). PANC-1 and BxPC3 cells were seeded in a CellCarrier 96-well microplates (PerkinElmer) overnight and treated with PBS, TTCI NPs or CPI-613. Then, the 96-well microplate was placed into the High Content analysis system for incubation. At appropriate intervals, digital phase contrast images of cells were captured. The scale bar was $100 \mu \mathrm{m}$.

\subsection{Intracellular Distributions}

BxPC3 cells were seeded in CellCarrier 96-well microplates overnight and treated with TTCI/Rho NPs $(20 \mu \mathrm{M})$. Intracellular distributions of TTCI/Rho NPs for different time $(0.5,2$ and $4 \mathrm{~h})$ were observed by using the High Content analysis system. Average fluorescence intensity of the picture was quantified by Image J software (Image J 1.49, Wayne Rasband National Institutes of Health, Bethesda, MD, USA).

\subsection{Mitochondria Targeted Imaging}

BxPC3 cells were seeded in CellCarrier 96-well microplates overnight and treated with TTCI/Rho NPs $(20 \mu \mathrm{M})$ for 0.5 or $4 \mathrm{~h}$. The cells were stained with Mito-Tracker Green $(\lambda \mathrm{ex}=488 \mathrm{~nm}, \lambda \mathrm{em}=516 \mathrm{~nm})$ for $30 \mathrm{~min}$. Images were acquired using the High Content analysis system. The colocalization in the magnification box was quantified by Image J software.

\subsection{Cell Apoptosis Assay}

Apoptosis induced by the TTCI NPs in BxPC 3 cells was analyzed by flow cytometry (Becton Dickinson, AccuriTM C6, Franklin Lakes, NJ, USA). PBS and CPI-613 were used as a control. The Annexin V-FITC Apoptosis Detection Kit was used according to the manufacturer's instructions. Briefly, the BxPC3 cells were treated with PBS, TTCI NPs or CPI-613 for $48 \mathrm{~h}$. The cells were harvested and washed twice with cold PBS and then stained with PI and annexin V-FITC for $15 \mathrm{~min}$ at room temperature. The PI/annexin V-FITC signal was determined using flow cytometry.

\section{Results and Discussion}

\subsection{Synthesis and Characterization of the Lipid Prodrug}

The lipid prodrug was synthesized by conjugating model drug CPI-613 and mitochondrial targeting ligand TPP with thioketal skeleton, as shown in Scheme 1. In brief, thioketal linkage (compound 2 ) was prepared by reduction of compound $\mathbf{1}$, which was synthesized by 3-mercaptopropionic acid and anhydrous acetone under a catalytic amount of trifluoroacetic acid. Then the (3-carboxypropyl) triphenyl phosphonium bromide (targeting ligand TPP) was conjugated onto one end of skeleton 2 in the presence of DCC and DMAP to give precursor 3 . Subsequently, the target mitochondria-targeted prodrug 4 (represented as TTCI based on the abbreviation of different functional groups) was obtained by coupling anticancer drug molecule CPI-613 to the other end of the linkage under the same conditions. For comparison, cholesterol analogue TTCh using cholesterol instead of CPI-613 was also prepared through a similar method. All novel compounds in each step were purified and their structures were confirmed by ${ }^{1} \mathrm{H}$ NMR, ${ }^{13} \mathrm{C}$ NMR and HRMS.

\subsection{Preparation and Characterization of CPI-613-Prodrug NPS}

After the successful synthesis of TTCI and TTCh, the self-assembly abilities of TTCI were evaluated. Polyethylene glycol (PEG) in particular has been widely used to modify the surface of nanoparticles because it has several unique advantages such as hydrophilicity, non-antigenicity and non-immunogenicity. Hence, nanoparticles can avoid uptake by macrophages and plasma opsonization when their surface is engineered using PEG. This results in the realization of prolonged circulation time, improved nanoparticles and in- 
creased tumor targeting via the "enhanced permeability and retention" (EPR) effect [32,33]. Therefore, DSPE-PEG2000, which has been approved for clinical use by the U.S. Food and Drug Administration (FDA), was added to improve the performance of liposome NPs self-assembled via TTCI. CPI-613-prodrug NPs were constructed with TTCI:DSPEPEG2000 at different molar ratios using the thin film hydration method [34]. First, the particle sizes of the prepared NPs with different composition proportions were measured by dynamic light scattering (DLS). As shown in Figure 1A, prodrug NPs with a lower content of DSPE-PEG2000 (TTCI:DSPE-PEG2000 $=1: 0.05)$ had a larger particle size $(\sim 70 \mathrm{~nm})$. With increased of DSPE-PEG2000 content, prodrug NPs which were constructed with TTCI:DSPE-PEG2000 at molar ratios of 1:0.1, 1:0.2 and 1:0.3 had much smaller particle sizes $(\sim 30 \mathrm{~nm})$, with no obvious difference between them. The PDI values of these NPs were $0.256,0.407,0.468$ and 0.669 , respectively. The PDI values increased with the increase of DSPE-PEG2000. Subsequently, MTT-based cell viability assays were carried out in PNAC-1 and AsPC-1 cells in order to investigate the effect of composition ratio on cytotoxicity. It was found that prodrug NPs constructed with TTCI:DSPE-PEG2000 at a molar ratio of 1:0.2 exhibited the best in vitro antitumor activity when the concentration of CPI-613 was over $10 \mu \mathrm{M}$, in both cell lines (Figure S1). Therefore, CPI-613-prodrug NPs which were constructed with TTCI:DSPE-PEG2000 at a molar ratio of 1:0.2 were chosen for the following model example. Herein, transmission electron microscopy (TEM) was used to visually study the morphological characteristics of the prodrug NPs constructed with TTCI:DSPE-PEG2000 at a molar ratio of 1:0.2. The image in Figure 1B shows that those NPs have spherical distribution, with diameters ranging from $20 \mathrm{~nm}$ to $50 \mathrm{~nm}$. What is more, TTCI NPs reveal good stability (Figure S2) and have a $0.505 \mathrm{mV}$ surface charge (Figure S3).

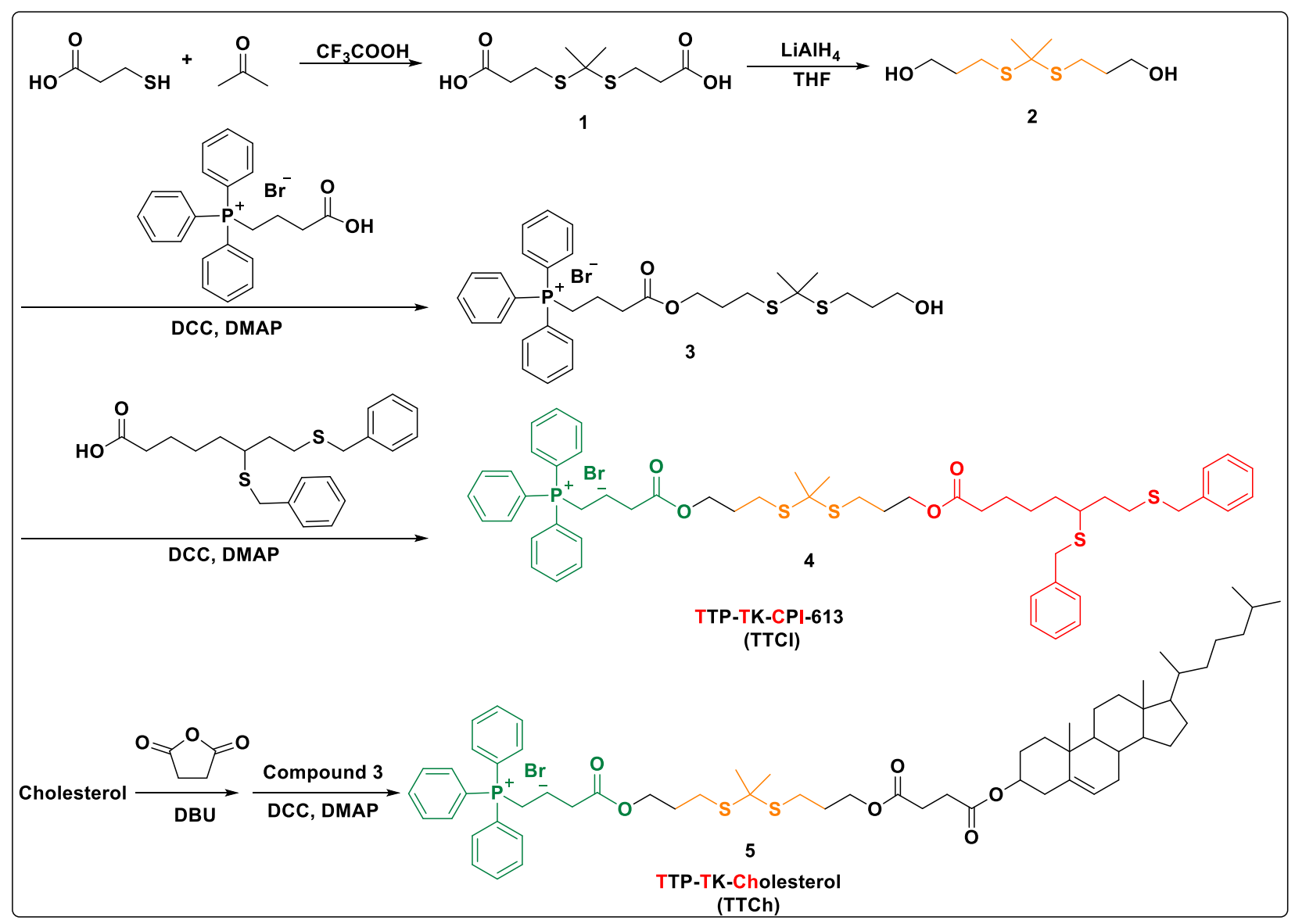

Scheme 1. Synthetic routes of target lipid prodrugs and analogues. 

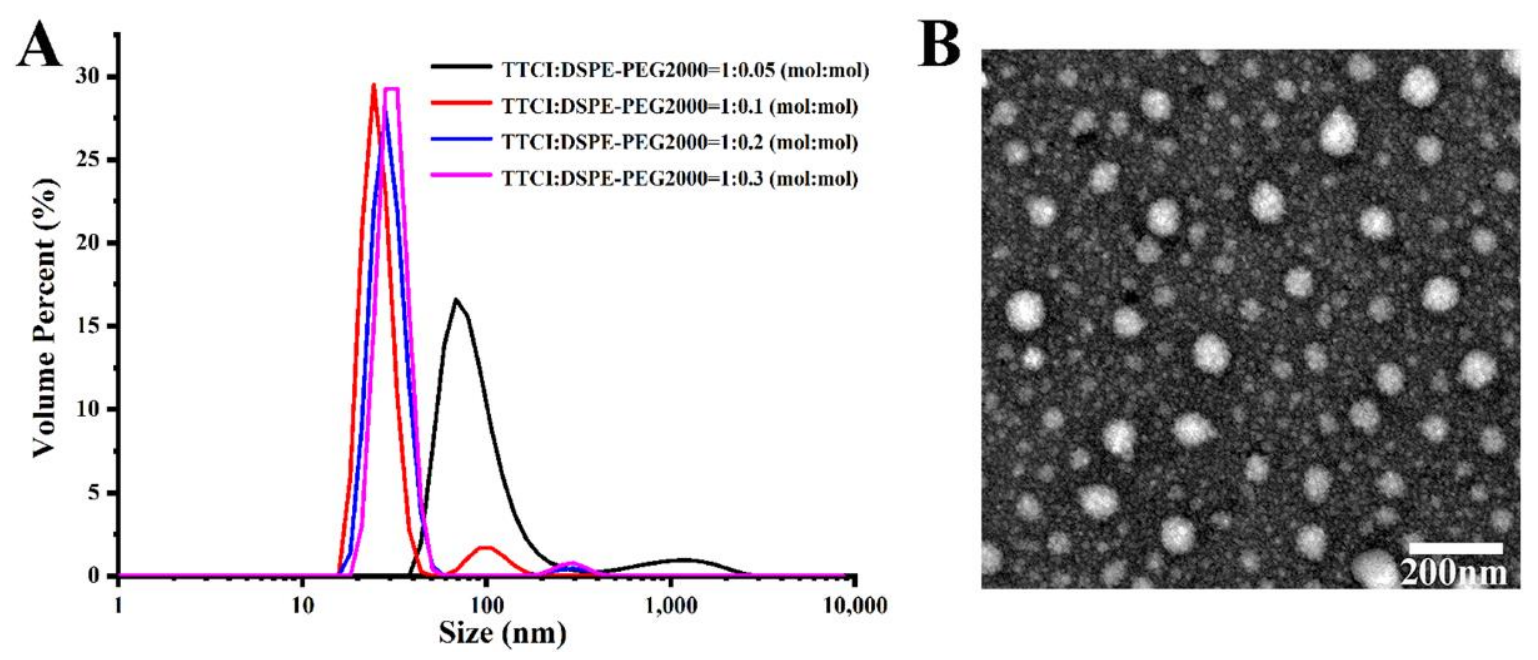

Figure 1. (A) Size distribution of CPI-613-prodrug NPs constructed with different molar ratios of TTCI:DSPEPEG2000. (B) The TEM image of CPI-613-prodrug NPs constructed with TTCI:DSPE-PEG2000 at a molar ratio of 1:0.2. Scale bar $=200 \mathrm{~nm}$.

\subsection{Measurement of ROS-Responsive TTCI NPs Degradation In Vitro}

The thioketal linkers between TPP and CPI-613 can respond to ROS. To investigate this responsive behavior, the size changes of TTCI NPs were monitored over time after treatment with different concentrations of ROS. As shown in Figure 2, at a low ROS concentration ( $200 \mathrm{mM} \mathrm{H}_{2} \mathrm{O}_{2}$ in the presence of $\mathrm{Fe}^{2+}$ ) for $4 \mathrm{~h}$ incubation, the size changes of TTCI NPs were not obvious. However, with the extension of incubation time to $24 \mathrm{~h}$, the size of the TTCI NPs increased and a new peak appeared at about $400 \mathrm{~nm}$, indicating the destruction of NPs. The size of TTCI NPs increased from $30 \mathrm{~nm}$ to about $400 \mathrm{~nm}$ after incubation with $700 \mathrm{mM} \mathrm{H}_{2} \mathrm{O}_{2}$ for 3.5 days, which can be attributed to the degradation of the thioketal group triggered by ROS, resulting in the separation of TPP and CPI-613 from the TTCI. Similar results were found with TTCh NPs (Figure S4). This feature may enable more CPI-613 molecules to be released at the active site, further improving therapeutic efficacy.

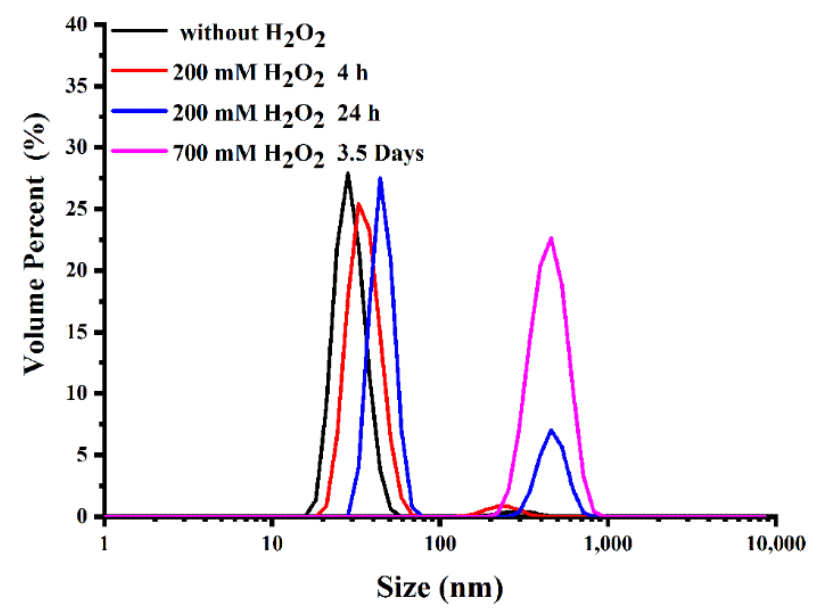

Figure 2. Size distribution of TTCI NPs after treatment with various $\mathrm{H}_{2} \mathrm{O}_{2}$ concentrations for different times.

\subsection{Cellular Internalization and the Specific Mitochondria-Targeting Function of the TTCI NPs}

For evaluation of the cellular uptake behavior of TTCI NPs, Rhodamine B base (or Nile Red), a fluorescent dye, was encapsulated in TTCI NPs to form Rhodamine B-loaded TTCI NPs (TTCI/Rho NPs) to permit indirect observation with a fluorescence microscope, 
as the prodrug TTCI has no inherent fluorescence. Confocal laser scanning microscopy (CLSM) with a high content analysis system was applied in order to visually examine the internalization and intracellular location of TTCI/Rho NPs at the concentration of $20 \mu \mathrm{M}$ in Pancreatic Carcinoma line-3 (BxPC3 cells). The fluorescence intensity detected in cells can clearly indicate the concentration of these systems internalized into the cells. As shown in Figure S5A, a considerable amount of the yellow fluorescent signal of Rhodamine B could be observed after $30 \mathrm{~min}$, indicating rapid and high cellular uptake of TTCI/Rho NPs. It can be also seen that the fluorescence signals in the cells increased gradually with the extension of incubation time (from $0.5 \mathrm{~h}$ to $4 \mathrm{~h}$ ). The mean intensity of Rhodamine B fluorescence in the images at different incubation times was calculated using imageJ software (Figure S5B). The mean fluorescence intensity increased gradually with the extension of incubation time, which was mostly consistent with the visual results. This suggests that TTCI/Rho NPs exhibited fast and efficient cellular internalization, which is necessary for the following delivery process.

Subsequently, the possibility of targeting mitochondria was further investigated using mitochondria and TTCI NPs labeled/stained with MitoTracker Green and Rhodamine B or Nile Red (NR), respectively. BxPC3 cells were incubated with TTCI/Rho NPs at a concentration of $20 \mu \mathrm{M}$ for $0.5 \mathrm{~h}$ and $4 \mathrm{~h}$ and with the commercial mitochondrial dye MitoTracker Green at $37^{\circ} \mathrm{C}$ for $0.5 \mathrm{~h}$, respectively. The images were captured by high content analysis system-Operetta CLS ${ }^{\mathrm{TM}}$ after 0.5 and $4 \mathrm{~h}$ of incubation (Figure $3 \mathrm{~A}$ ). It was found that after 0.5 and $4 \mathrm{~h}$ the cells treated with TTCI/Rho NPs showed obvious co-localization between the mitochondrial probes MitoTracker Green and Rhodamine B encapsulated by TTCI NPs. Abundant colocalization fluorescent signals were especially found after $4 \mathrm{~h}$ incubation, indicating that the targeted prodrugs can easily realize our purpose for preferably targeting internalized mitochondria in living cells. The cross-section fluorescence intensity of Rhodamine B and MitoTracker Green in the enlarged regions was further analyzed using imageJ software (Figure 3B). It was found that the fluorescence change trend of two dyes was the same, further confirming the excellent co-localization of mitochondria and delivered cargos. Similar results were obtained for TTCI/NR NPs (Figure S6). These observations reveal the potential of TPP modified prodrugs such as TTCI to deliver CPI-613 to mitochondria, and to further exert therapeutic effects after accumulating in mitochondria.

\subsection{In Vitro Antitumor Activity}

It has been reported that CPI-613 exhibits prominent antitumor activity, especially against human pancreatic cancer $[1,3,4]$. Therefore, in this work, three human pancreatic cell lines (PANC-1, AsPC-1 and BxPC3) were used as the models for the MTT assay. Firstly, the cytotoxicity of nanocarriers without encapsulation of CPI-613 was measured to prove that the drug carriers are biocompatible. A lipid prodrug counterpart was synthesized by simply replacing the CPI-613 molecule with biocompatible cholesterol, represented as TTCh (TPP-TK-Cholesterol) for short. The TTCh NPs were constructed using the same method as TTCI NPs, with TTCh:DSPE-PEG2000 at a molar ratio of 1:0.2. The cytotoxicity of TTCI NPs and TTCh NPs against AsPC- 1 and PANC- 1 cells were investigated at various concentrations. As shown in Figure S7, the TTCh NPs without loaded CPI-613 presented little cytotoxicity in both AsPC-1 and PANC-1 cells, and cellular viability remained over $90 \%$ for concentrations in the range of $0.1 \mu \mathrm{M}$ to $50 \mu \mathrm{M}$. In contrast, TTCI NPs containing CPI-613 showed significant cytotoxicity in both cells when the concentration was greater than $20 \mu \mathrm{M}$. The cell viability percentages remained at about $20 \%$ when treated with $50 \mu \mathrm{M}$ TTCI NPs. The above results indicate that the CPI-613 conjugated to the prodrug plays a vital role in cytotoxicity. 
A

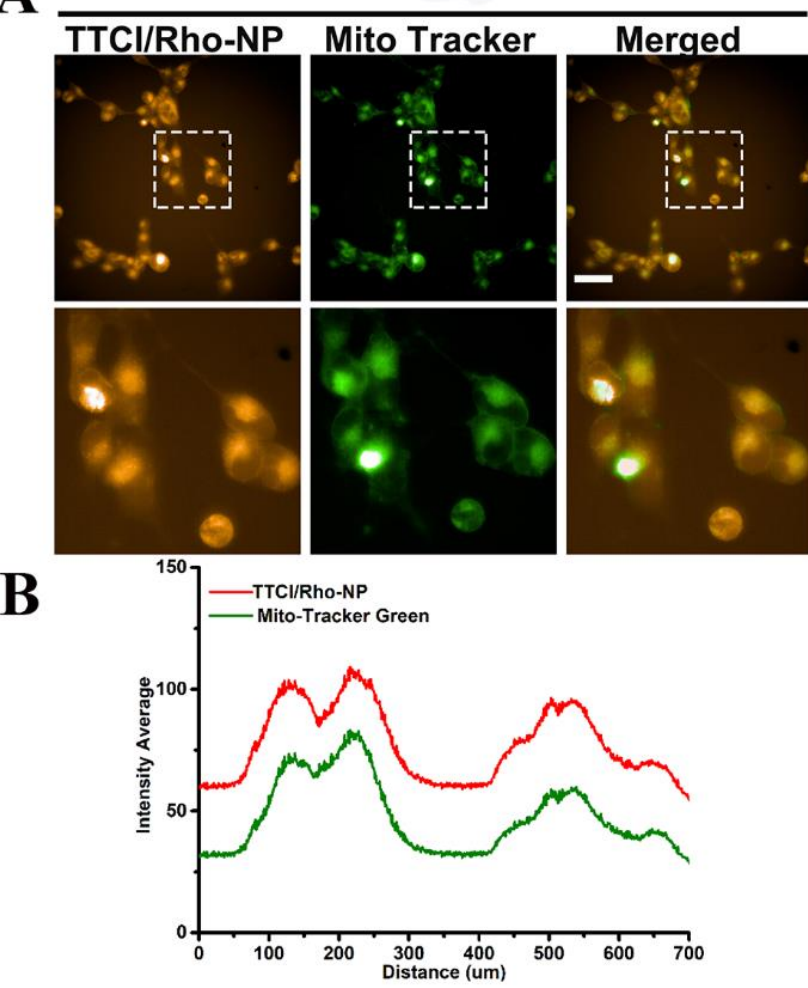

$4 \mathrm{~h}$
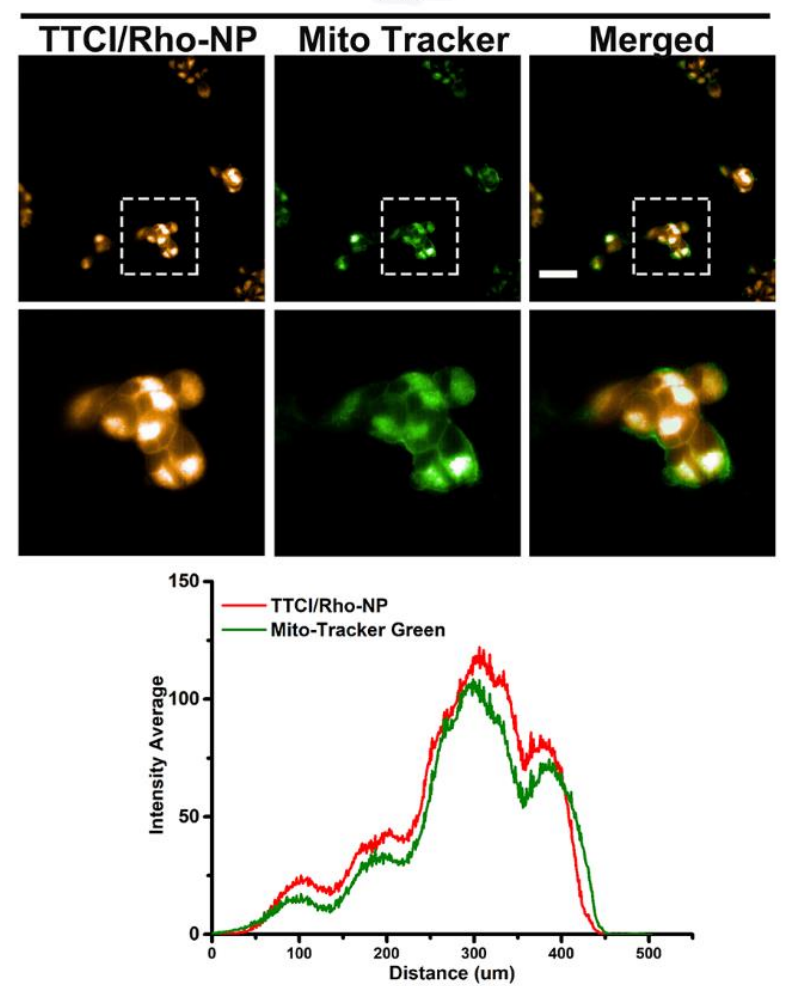

Figure 3. Mitochondria-targeting ability of TTCI/Rho NPs in vitro: Images of the BxPC3 cells treated with TTCI/Rho NPs at a concentration of $20 \mu \mathrm{M}$ for 0.5 and $4 \mathrm{~h}$, captured by high content analysis system-operetta CLS ${ }^{\mathrm{TM}}$. For each row, from left to right: TTCI/Rho NPs (546 nm excitations); mitochondria stained by MitoTracker Green (488 nm excitation); merged image (A). Scale bars: $50 \mu \mathrm{m}$. The cross-section fluorescence intensity of Rhodamine B and MitoTracker Green in the enlarged regions analyzed using imageJ software (B).

Subsequently, these three cell lines were used to investigate the in vitro anticancer efficiency of CPI-613-loaded supramolecular nanoplatforms. As shown in Figure 4A-C, after three kinds of human pancreatic cells were co-incubated with TTCI NPs at different CPI-613 concentrations, TTCI NPs presented dose-dependent cytotoxicity against PANC-1, AsPC- 1 and BxPC 3 cells, and the cell viabilities decreased obviously with the concentration of CPI-613, increasing from $10 \mu \mathrm{M}$ to $50 \mu \mathrm{M}$. In contrast, the cellular viability remained over $90 \%$ for pure CPI-613 in all cell lines even with a concentration of drug up to $50 \mu \mathrm{M}$, indicating that CPI-613 encapsulated with TTCI NPs had a more significant ability to kill pancreatic cancer cells than free CPI-613. Meanwhile, the IC $_{50}$ values of TTCI NPs in the three cells were around 20-30 $\mu \mathrm{M}$, which was far lower than that of CPI-613 (reported around $200 \mu \mathrm{M}$ [1]). Such a dramatic difference in $\mathrm{IC}_{50}$ values reveals the successful targeting effect and ROS-responsive release of TTCI NPs, which facilitated the accumulation of CPI-613 at its acting site mitochondria. Moreover, the above results can also be supported by the morphology and number of living cells for PBS: $20 \mu \mathrm{M}$ of TTCI NPs, $50 \mu \mathrm{M}$ of TTCI NPs and $50 \mu \mathrm{M}$ of free CPI-613, respectively (Figure 4D). The high content analysis system-operetta CLS ${ }^{\mathrm{TM}}$ was used to assess BxPC3 cell proliferation. The results showed that it induced a dramatic decrease in the total number of cells with $50 \mu \mathrm{M}$ of TTCI NPs. However, cell proliferation was not affected by PBS and $50 \mu \mathrm{M}$ of free CPI-613. Atrophy and deformation of PANC- 1 cells appeared after $2 \mathrm{~h}$ co-incubation with $50 \mu \mathrm{M}$ of TTCI NPs. Similar results were found in PANC-1 cells (Figure S8). The IC 50 values of TTCI prodrug and TTCI NPs were not significantly different, and digital phase contrast images of living BxPC 3 cells showed that it induced a dramatic decrease in the total number of cells with both $50 \mu \mathrm{M}$ of TTCI prodrugs and TTCI NPs (Figure S9). However, the TTCI prodrugs are practically insoluble (dissolved in DMSO for biological experiments), which will severely 
restrict biological application. The evidence intuitively revealed that TTCI NPs had much better in vitro anticancer capacity. Therefore, all the above results imply that encapsulated CPI-613 TTCI NPs can be efficiently delivered to mitochondria and released in the ROS-enriched environment in mitochondria, resulting in an accumulation of therapeutic molecules which can efficiently inhibit the proliferation of pancreatic cancer cells.

A

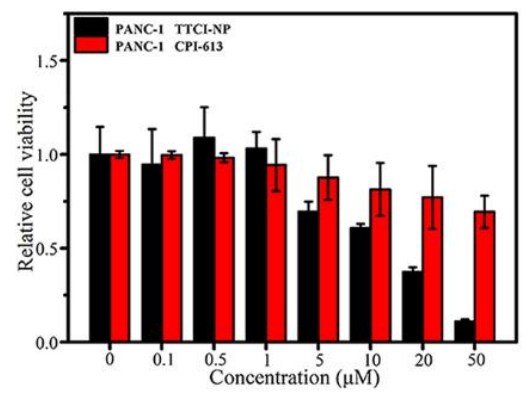

B

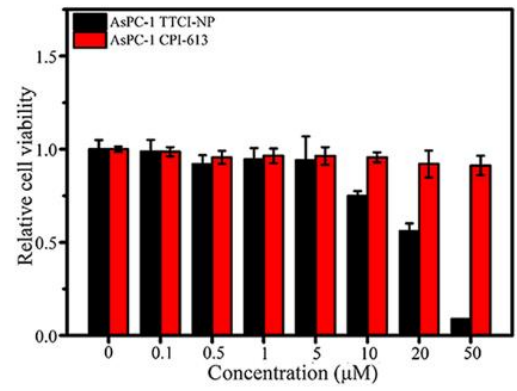

C

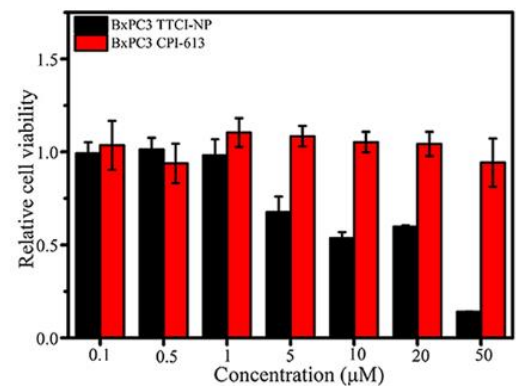

D
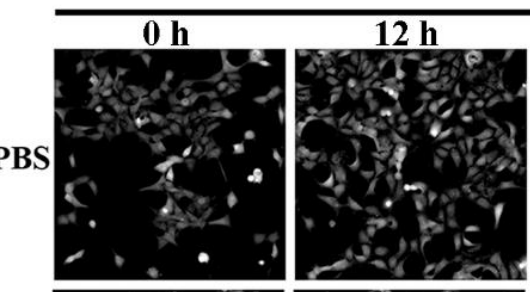

BxPC3 cells

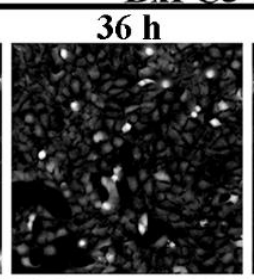

$72 \mathrm{~h}$
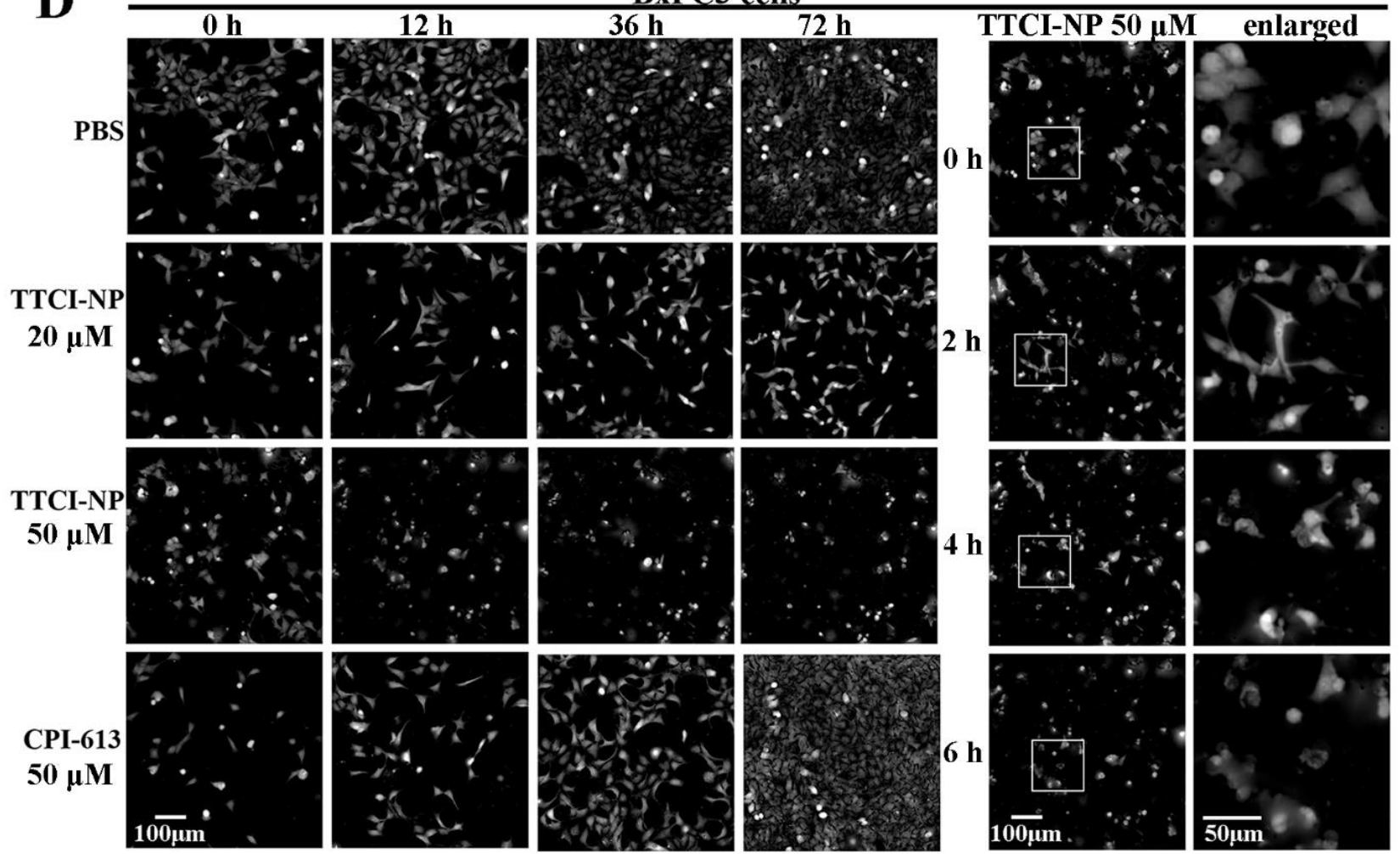

Figure 4. In vitro cytotoxicity of free CPI-613 and CPI-613-loaded TTCI NPs at various concentrations against PANC-1 cells (A), AsPC-1 cells (B), and BxPC3 cells (C) after $48 \mathrm{~h}$ incubation. Data represent mean \pm SD $(n=3)$. Digital phase contrast images of living BxPC3 cells (D) treated with PBS, $20 \mu \mathrm{M}$ TTCI NPs, $50 \mu \mathrm{M}$ TTCI NPs and $50 \mu \mathrm{M}$ CPI-613 at different times. Digital phase contrast images were captured by high content analysis system-operetta CLS ${ }^{\mathrm{TM}}$. Scale bar: $100 \mu \mathrm{m}$ and $50 \mu \mathrm{m}$ (for enlarged images).

\subsection{Cell Apoptosis}

CPI-613 could induce pancreatic cancer apoptosis by disrupting mitochondrial metabolism [4]. Therefore, low cytometry analysis was performed after FITC Annexin $\mathrm{V} / \mathrm{PI}$ staining in order to further assess the apoptosis of $\mathrm{BxPC} 3$ cells induced by various therapeutics. As such, BxPC3 cells were treated with PBS, $50 \mu \mathrm{M}$ CPI-613, $20 \mu \mathrm{M}$ TTCI NPs and $50 \mu \mathrm{M}$ TTCI NPs as described above. After that, cell apoptosis was detected after further incubation for $48 \mathrm{~h}$. The results showed that the ratio of apoptosis to cells 
was $7.88 \%, 54.11 \%$ and $97.3 \%$ as induced by $50 \mu \mathrm{M}$ CPI-613, $20 \mu \mathrm{M}$ TTCI NPs and $50 \mu \mathrm{M}$ TTCI NPs, respectively (Figure 5). These data distinctly indicate that TTCI NPs can induce apoptosis in pancreatic cancer cells to a dramatic degree, especially at a concentration of $50 \mu \mathrm{M}$. This observation of in vitro antitumor activity and cell apoptosis together shows the huge potential of TTCI nanoplatforms for pancreatic cancer treatment.

A

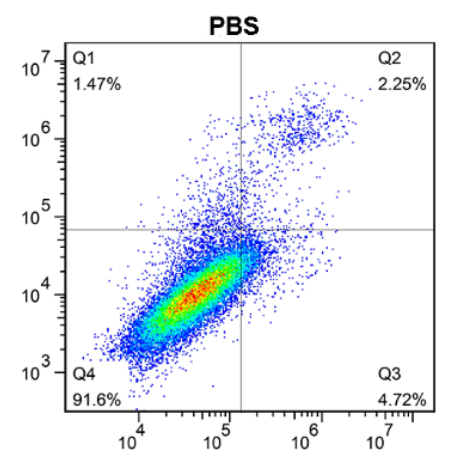

CPI-613 $50 \mu \mathrm{M}$

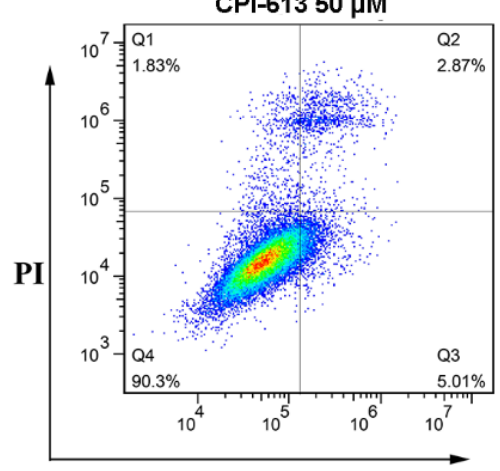

Annexin V-FITC
TTCI-NP $20 \mu \mathrm{M}$
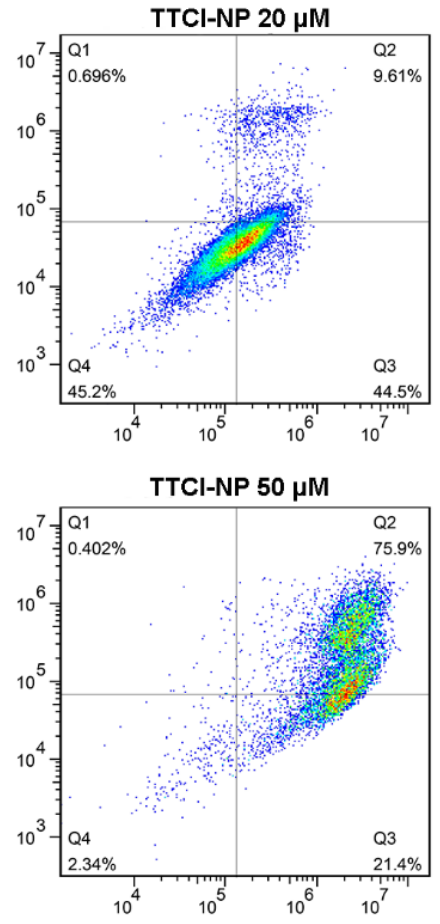

B

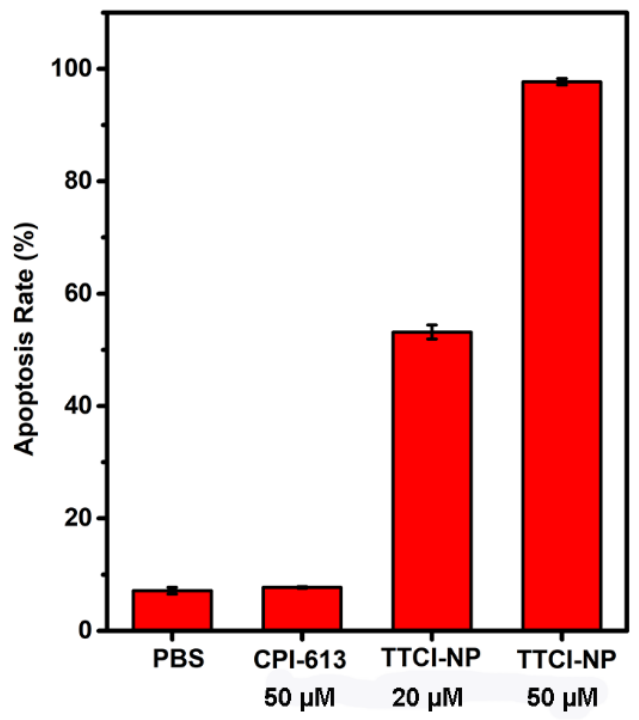

Figure 5. The effects on apoptosis of free CPI-613 and CPI-613-loaded TTCI NPs at various concentrations. BxPC3 cells were treated with $50 \mu \mathrm{M}$ CPI-613, $20 \mu \mathrm{M}$ TTCI NPs and $50 \mu \mathrm{M}$ TTCI NPs for $48 \mathrm{~h}$ and apoptosis was determined by flow cytometry with Annexin V-FITC/PI staining (A). The apoptosis rate (B) following treatment with various therapeutics.

\section{Conclusions}

In summary, a mitochondria-targeted and ROS-responsive prodrug TTCI was developed by conjugating the model drug CPI-613 and mitochondrial targeting ligand TPP with a thioketal linker. The prodrugs can self-assemble into stable nanoparticles (TTCI NPs) together with DSPE-PEG2000, with resulting unique properties including effective mitochondrial targeting, ROS-cleaving capability and robust therapeutic performance. In addition, the smart nanoplatform showed enhanced therapeutic effects on pancreatic cancer, mainly due to higher accumulation of nanoparticles in mitochondria induced by mitochondrial targeting, facilitating the targeted delivery of CPI-613 to its active site. The results with respect to in vitro antitumor activity and cell apoptosis revealed that the $\mathrm{IC}_{50}$ values of TTCI NPs in three pancreatic cancer cell lines were around $20 \mu \mathrm{M}-30 \mu \mathrm{M}$, which was far lower than that of CPI-613 $(200 \mu \mathrm{M})$, and that $50 \mu \mathrm{M}$ TTCI NPs could increase apoptosis by as much as $97.3 \%$ in BxPC3 cells. Therefore, our study provides a potential strategy for developing safe, targeted and efficient drug delivery systems for use in pancreatic cancer therapy.

Supplementary Materials: The following are available online at https: / www.mdpi.com/article/ 10.3390/nano11112875/s1. Figure S1: In vitro cytotoxicity of TTCI NPs constructed with different molar ratios of TTCI:DSPE-PEG2000 in PNAC-1 (A) and AsPC-1 (B) cells treated with various concentrations for $48 \mathrm{~h}$. Data represent mean $\pm \mathrm{SD}(n=3)$. Figure S2: Mean particle sizes of TTCI NPs constructed with TTCI:DSPE-PEG2000 at a molar ratio of 1:0.2 at different time points (DLS 
at room temperature). Data represent mean $\pm \mathrm{SD}(n=3)$. Figure S3: Zeta-potentials of TTCI NPs constructed with TTCI:DSPE-PEG2000 at a molar ratio of 1:0.2 (DLS at room temperature). Figure S4: Size distribution of TTCh NPs after treatment with $700 \mathrm{mM} \mathrm{H}_{2} \mathrm{O}_{2}$ for different times. Figure S5: Images of the BxPC-3 cells treated with Rhodamine B-loaded TTCI/Rho NPs at a concentration of $20 \mu \mathrm{M}$ for 0.5 , 2, and $4 \mathrm{~h}$, respectively. For each row, left: TTCI/Rho NPs; middle: bright field; right: merged image. The images were captured by high content analysis system-operetta CLS ${ }^{\mathrm{TM}}(\mathrm{A})$. Scale bars: $50 \mu \mathrm{m}$. The mean intensity of rhodamine fluorescence in the images at different incubation times as calculated using imageJ software (B). Figure S6: Mitochondria-targeting ability of TTCI/NR NPs in vitro: Images of the BxPC3 cells treated with TTCI/NR NPs at the concentration of $20 \mu \mathrm{M}$ for $0.5,2$ and $4 \mathrm{~h}$ captured by high content analysis system-operetta CLS ${ }^{\mathrm{TM}}$. For each row, from left to right: TTCI/NR NPs; mitochondria stained by MitoTracker Green; merged image. Scale bars: $50 \mu \mathrm{m}$. Figure S7: Cell viability of AsPC-1 (A) and PANC-1 (B) cells after being treated with different concentrations of TTCI NPs and TTCh NPs for $48 \mathrm{~h}$. Data represent mean \pm SD $(n=3)$. Figure S8: Digital phase contrast images of living BxPC-3 cells (D) treated with PBS, $20 \mu \mathrm{M}$ TTCI NPs, $50 \mu \mathrm{M}$ TTCI NPs and $50 \mu \mathrm{M}$ CPI-613 at different times. Digital phase contrast images were captured by high content analysis system-operetta CLS ${ }^{\mathrm{TM}}$. Scale bar: $100 \mu \mathrm{m}$ and $50 \mu \mathrm{m}$ (for enlarged images). Figure S9: In vitro cytotoxicity of TTCI prodrugs (A) and TTCI NPs (B) at various concentrations against BxPC3 cells after $48 \mathrm{~h}$ incubation. Digital phase contrast images of living BxPC3 cells were captured by high content analysis system-operetta CLS ${ }^{\mathrm{TM}}$ treated with TTCI prodrugs and TTCI NPs at various concentrations.

Author Contributions: Y.-M.Z., Z.-Z.C., B.-C.W. and Z.H. conceived and designed the experiments; Y.M.Z., M.X., R.A., L.-X.G. and Y.T. performed the experiments; J.-H.H. performed CLSM related experiments; Y.-M.Z. and Y.-F.L. analyzed the data; Z.H. and Y.-M.Z. contributed reagents/materials/analysis tools; Z.H. wrote the paper; Z.-Z.C. and B.-C.W. monitored and guided the whole process of designing and performing the experiments, contributing the methods and infrastructure, interpreting and discussing the data, and improving the manuscript. All authors have read and agreed to the published version of the manuscript.

Funding: This research was funded by the National Natural Science Foundation of China (Grant No. 21907012), Chongqing Natural Science Foundation (Grant No. cstc2019jcyj-msxmX0766 and NO. cstc2020jcyj-msxmX0908), Science and Technology Research Program of Chongqing Municipal Education Commission (Grant No. KJQN201901341 and No. KJQN201901329) and Science \& Technology Research Program of Chongqing University of Arts and Sciences (No. R2018SBX12 and R2018SCH09).

Institutional Review Board Statement: Not applicable.

Informed Consent Statement: Not applicable.

Acknowledgments: Thanks for Zhi-Gang Xu for polishing the English language and style.

Conflicts of Interest: The authors declare no conflict of interest.

\section{References}

1. Gao, L.; Xu, Z.; Huang, Z.; Tang, Y.; Yang, D.; Huang, J.; He, L.; Liu, M.; Chen, Z.; Teng, Y. CPI-613 rewires lipid metabolism to enhance pancreatic cancer apoptosis via the AMPK-ACC signaling. J. Exp. Clin. Cancer Res. 2020, 39, 1-12. [CrossRef] [PubMed]

2. Sausen, M.; Phallen, J.; Adleff, V.; Jones, S.; Leary, R.J.; Barrett, M.T.; Anagnostou, V.; Parpart-Li, S.; Murphy, D.; Kay Li, Q.; et al. Clinical implications of genomic alterations in the tumour and circulation of pancreatic cancer patients. Nat. Commun. 2015, 6, 7686. [CrossRef] [PubMed]

3. Lee, K.C.; Maturo, C.; Perera, C.N.; Luddy, J.; Rodriguez, R.; Shorr, R. Translational assessment of mitochondrial dysfunction of pan-creatic cancer from in vitro gene microarray and animal efficacy studies, to early clinical studies, via the novel tumor-specific an-ti-mitochondrial agent, CPI-613. Ann. Transl. Med. 2014, 2. [CrossRef]

4. Alistar, A.; Morris, B.B.; Desnoyer, R.; Klepin, H.D.; Hosseinzadeh, K.; Clark, C.; Cameron, A.; Leyendecker, J.; D’Agostino, R.; Topaloglu, U.; et al. Safety and tolerability of the first-in-class agent CPI-613 in combination with modified FOLFIRINOX in patients with metastatic pancreatic cancer: A single-centre, open-label, dose-escalation, phase 1 trial. Lancet Oncol. 2017, 18, 770-778. [CrossRef]

5. Zachar, Z.; Marecek, J.; Maturo, C.; Gupta, S.; Stuart, S.D.; Howell, K.; Schauble, A.; Lem, J.; Piramzadian, A.; Karnik, S.; et al. Non-redox-active lipoate derivates disrupt cancer cell mitochondrial metabolism and are potent anticancer agents in vivo. J. Mol. Med. 2011, 89, 1137-1148. [CrossRef] 
6. Pardee, T.S.; Lee, K.; Luddy, J.; Maturo, C.; Rodriguez, R.; Isom, S.; Miller, L.; Stadelman, K.M.; Levitan, D.; Hurd, D.; et al. A Phase I Study of the First-in-Class Antimitochondrial Metabolism Agent, CPI-613, in Patients with Advanced Hematologic Malignancies. Clin. Cancer Res. 2014, 20, 5255-5264. [CrossRef] [PubMed]

7. Lycan, T.W.; Pardee, T.S.; Petty, W.J.; Bonomi, M.; Alistar, A.; Lamar, Z.S.; Isom, S.; Chan, M.D.; Miller, A.A.; Ruiz, J. A Phase II Clinical Trial of CPI-613 in Patients with Relapsed or Refractory Small Cell Lung Carcinoma. PLoS ONE 2016, 11, e0164244. [CrossRef]

8. $\quad$ Li, Y.; Zhao, Z.; Liu, H.; Fetse, J.P.; Jain, A.; Lin, C.-Y.; Cheng, K. Development of a Tumor-Responsive Nanopolyplex Targeting Pancreatic Cancer Cells and Stroma. ACS Appl. Mater. Interfaces 2019, 11, 45390-45403. [CrossRef]

9. Li, J.; Yang, X.-L.; Liu, Y.-H.; Wu, W.-X.; Liu, B.-Y.; Wang, N.; Yu, X.-Q. Chemoenzymatic synthesis of dual-responsive graft copolymers for drug delivery: Long-term stability, high loading and cell selectivity. J. Mater. Chem. B 2018, 6, 6993-7003. [CrossRef] [PubMed]

10. Liu, B.-Y.; Wu, W.-X.; Liu, Y.-H.; Jia, C.; Yang, X.-L.; Li, J.; Wang, N.; Yu, X.-Q. Water-soluble mitochondria-targeting polymeric prodrug micelles for fluorescence monitoring and high intracellular anticancer efficiency. Polym. Chem. 2017, 8, 5982-5987. [CrossRef]

11. Torchilin, V.P.; Khaw, B.-A.; Weissig, V. Intracellular targets for DNA delivery: Nuclei and mitochondria. Somat. Cell Mol. Genet. 2002, 27, 49-64. [CrossRef] [PubMed]

12. He, H.; Meng, S.; Li, H.; Yang, Q.; Xu, Z.; Chen, X.; Sun, Z.; Jiang, B.; Li, C. Nanoplatform based on GSH-responsive mesoporous silica nanoparticles for cancer therapy and mitochondrial targeted imaging. Microchim. Acta 2021, 188, 1-10. [CrossRef] [PubMed]

13. Xu, Z.; Chen, X.; Sun, Z.; Li, C.; Jiang, B. Recent progress on mitochondrial targeted cancer therapy based on inorganic nanomaterials. Mater. Today Chem. 2019, 12, 240-260. [CrossRef]

14. Sung, J.; Rho, J.G.; Jeon, G.G.; Chu, Y.; Min, J.S.; Lee, S.; Kim, J.H.; Kim, W.; Kim, E. A New Infrared Probe Targeting Mitochondria via Regulation of Molecular Hydrophobicity. Bioconjugate Chem. 2018, 30, 210-217. [CrossRef] [PubMed]

15. Liew, S.S.; Qin, X.; Zhou, J.; Li, L.; Huang, W.; Yao, S.Q. Smart Design of Nanomaterials for Mitochondria-Targeted Nanotherapeutics. Angew. Chem. Int. Ed. 2021, 60, 2232-2256. [CrossRef]

16. Jhaveri, A.; Torchilin, V. Intracellular delivery of nanocarriers and targeting to subcellular organelles. Expert Opin. Drug Deliv. 2016, 13, 49-70. [CrossRef] [PubMed]

17. Lu, P.; Bruno, B.J.; Rabenau, M.; Lim, C.S. Delivery of drugs and macromolecules to the mitochondria for cancer therapy. J. Control. Release 2016, 240, 38-51. [CrossRef] [PubMed]

18. Faria, R.; Albuquerque, T.; Neves, A.R.; Bhatt, H.; Biswas, S.; Cardoso, A.M.; de Lima, M.C.P.; Jurado, A.S.; Costa, D. Physicochemical characterization and targeting performance of triphenylphosphonium nano-polyplexes. J. Mol. Liq. 2020, $316,113873$. [CrossRef]

19. Mani, S.; Swargiary, G.; Tyagi, S.; Singh, M.; Jha, N.K.; Singh, K.K. Nanotherapeutic approaches to target mitochondria in cancer. Life Sci. 2021, 281, 119773. [CrossRef]

20. Yousif, L.F.; Stewart, K.M.; Kelley, S.O. Targeting Mitochondria with Organelle-Specific Compounds: Strategies and Applications. ChemBioChem 2009, 10, 1939-1950. [CrossRef]

21. Bielski, E.R.; Zhong, Q.; Brown, M.; da Rocha, S.R.P. Effect of the Conjugation Density of Triphenylphosphonium Cation on the Mitochondrial Targeting of Poly(amidoamine) Dendrimers. Mol. Pharm. 2015, 12, 3043-3053. [CrossRef] [PubMed]

22. Zhang, X.-Y.; Zhang, P.-Y. [Retracted] Mitochondria targeting nano agents in cancer therapeutics (Review). Oncol. Lett. 2020, $20,1$. [CrossRef] [PubMed]

23. Ozsvari, B.; Sotgia, F.; Lisanti, M.P. Exploiting mitochondrial targeting signal(s), TPP and bis-TPP, for eradicating cancer stem cells (CSCs). Aging 2018, 10, 229-240. [CrossRef]

24. Murphy, M.P.; Holmgren, A.; Larsson, N.-G.; Halliwell, B.; Chang, C.J.; Kalyanaraman, B.; Rhee, S.G.; Thornalley, P.J.; Partridge, L.; Gems, D.; et al. Unraveling the Bio-logical Roles of Reactive Oxygen Species. Cell Metab. 2011, 13, 361-366. [CrossRef] [PubMed]

25. Yang, B.; Wang, K.; Zhang, D.; Sun, B.; Ji, B.; Wei, L.; Li, Z.; Wang, M.; Zhang, X.; Zhang, H.; et al. Light-activatable dual-source ROS-responsive prodrug nanoplatform for synergistic chemo-photodynamic therapy. Biomater. Sci. 2018, 6, 2965-2975. [CrossRef] [PubMed]

26. Serrano, M.C.; Feito, M.J.; González-Mayorga, A.; Diez-Orejas, R.; Matesanz, M.C.; Portolés, M.T. Response of macrophages and neural cells in contact with reduced graphene oxide microfibers. Biomater. Sci. 2018, 6, 2987-2997. [CrossRef] [PubMed]

27. Shim, M.S.; Xia, Y. A Reactive Oxygen Species (ROS)-Responsive Polymer for Safe, Efficient, and Targeted Gene Delivery in Cancer Cells. Angew. Chem. Int. Ed. 2013, 52, 6926-6929. [CrossRef]

28. Yue, C.; Zhang, C.; Gabriel, A.; Yang, Y.; Jiang, X.; Yang, Y.; Pan, F.; Fuente, J.M.d.1.; Cui, D. Near-Infrared Light Triggered ROSactivated Theranostic Platform based on Ce6-CPT-UCNPs for Simultaneous Fluorescence Imaging and Chemo-Photodynamic Combined Therapy. Theranostics 2016, 6, 456-469. [CrossRef] [PubMed]

29. Li, Q.; Wen, Y.; You, X.; Zhang, F.; Shah, V.; Chen, X.; Tong, D.; Wei, X.; Yin, L.; Wu, J.; et al. Development of a reactive oxygen species (ROS)-responsive nanoplatform for targeted oral cancer therapy. J. Mater. Chem. B 2016, 4, 4675-4682. [CrossRef]

30. Lyu, Y.; He, S.; Li, J.; Jiang, Y.; Sun, H.; Miao, Y.; Pu, K. A Photolabile Semiconducting Polymer Nanotransducer for Near-Infrared Regulation of CRISPR/Cas9 Gene Editing. Angew. Chem. Int. Ed. 2019, 58, 18197-18201. [CrossRef] [PubMed] 
31. Wang, C.; Huang, B.; Yang, G.; Ouyang, Y.; Tian, J.; Zhang, W. NIR-Triggered Multifunctional and Degradable Nanoplatform Based on an ROS-Sensitive Block Copolymer for Imaging-Guided Chemo-Phototherapy. Biomacromolecules 2019, 20, 4218-4229. [CrossRef] [PubMed]

32. Van der Meel, R.; Fens, M.H.A.M.; Vader, P.; van Solinge, W.W.; Eniola-Adefeso, O.; Schiffelers, R.M. Extracellular vesicles as drug delivery systems: Lessons from the liposome field. J. Control. Release 2014, 195, 72-85. [CrossRef] [PubMed]

33. Lim, E.-K.; Kim, T.; Paik, S.; Haam, S.; Huh, Y.-M.; Lee, K. Nanomaterials for Theranostics: Recent Advances and Future Challenges. Chem. Rev. 2015, 115, 327-394. [CrossRef] [PubMed]

34. Huang, Z.; Zhao, D.-M.; Deng, X.; Zhang, J.; Zhang, Y.-M.; Yu, X.-Q. Functionalized Asymmetric Bola-Type Amphiphiles for Efficient Gene and Drug Delivery. Nanomaterials 2018, 8, 115. [CrossRef] [PubMed] 